\title{
Grinding Force and Heat of Titanium Alloy Abrasive Belt and Its Effect on
}

\section{Surface Integrity}

\author{
Ying Liu ${ }^{1,2} \cdot$ Jiayu $\mathrm{Xu}^{1} \cdot$ Guijian Xiao $^{1,2} \cdot \mathrm{Kun} \mathrm{Zhou}^{1,2} \cdot$ Gang Liu $^{1}$
}

\begin{abstract}
Key rotating parts such as integral blisks and blades of aero-engines are widely made of titanium alloys. Abrasive belt grinding is one of the effective methods to improve the surface integrity. However, the grinding process produces greater grinding force and higher Grinding temperature, which have an impact on surface quality. At present, the force-heat coupling relationship in the grinding process and its influence on surface quality have not been explored. In this paper, a titanium alloy belt experiment is carried out to detect the force and temperature in the grinding process, this paper explores the influence of the grinding process parameters on the grinding force and temperature, and analyzes the influence on surface integrity of the force and temperature in the grinding process. The results show that the decrease of the belt linear speed, the increase of the feed speed and the grinding depth leads to the increase of the grinding force, the decrease of the feed speed, the increase of the belt linear speed and the grinding depth cause the temperature to rise. The effect of grinding depth on grinding force and grinding temperature is the most significant And High grinding force and grinding temperature will cause the surface quality to deteriorate and even more serious defects. However, when the maximum temperature of the grinding temperature field reaches above $120^{\circ} \mathrm{C}$, the surface roughness of the workpiece decreases from $1.596 \mu \mathrm{m}$ to $1.093 \mu \mathrm{m}$, and the height of the surface undulation is reduced from $32 \mu \mathrm{m}$ to $19 \mu \mathrm{m}$. This paper provides a reference for improving the surface integrity of the grinding process.
\end{abstract}

Keywords: Belt grinding $\cdot$ Grinding force $\cdot$ Grinding temperature $\cdot$ Surface integrity

\section{Introduction}

Titanium alloy is widely used in aircraft, ships and other fields because of its excellent characteristics such as low density, high strength, heat resistance and corrosion resistance. However, due to the large margin in the milling process, in order to improve the machining efficiency and ensure the surface quality of titanium alloy, the traditional cutting and milling metho

\section{$\bowtie$ Guijian Xiao}

xiaoguijian@cqu.edu.cn

${ }^{1}$ College of Mechanical and Vehicle Engineering, Chongqing

University, Chongqing 400044, China

${ }^{2}$ State Key Laboratory of Mechanical Transmissions,

Chongqing University, Chongqing 400044, China ds generally can not meet the requirements for surface integrity $[1,2]$, so it is necessary to grind titanium alloy. In the grinding process, due to the large grinding depth, higher grinding force and grinding temperature will be produced in the grinding process, and the grinding force and grinding temperature have an important impact on the surface quality of the workpiece ground by abrasive belt. Therefore, it is of great significance to explore the variation law of grinding force and temperature in the process of belt grinding to improve grinding efficiency and surface quality.

For titanium alloy grinding, $\mathrm{Fu}$ [3] used slotted electroplated CBN grinding wheel for creep feed grinding of titanium alloy, which provided a research 
direction for efficient grinding of titanium alloy. Nosenko [4] used SiC grin-ding wheel to grind titanium alloy to explore the influence factors of titanium alloy surface roughness. Nosenko [5] deeply grinded titanium alloy under grinding wheel grinding and nongrinding conditions to explore the surface quality of titanium alloy. Wang et al. [6] explored the secondary selfsharpening performance of hollow ball mill particles in the process of Grinding Titanium Alloy with abrasive belt. Zhou et al. [7] explored the variation law of residual stress during belt grinding and established a residual stress model based on molecular dynamics method. Zhu et al. [8] carried out the experiment of robot abrasive belt grinding titanium alloy, and explored the cutting mechanism of abrasive belt grinding titanium alloy from the perspective of energy.

With regard to the research on grinding force, grinding temperature and their influence on surface integrity, Yao et al. [9] studied the influence of different process parameters on grinding temperature and surface quality when grinding Inconel 718 with ceramic alumina grinding wheel and cubic borax carbide wheel, and explained how belt grinding and polishing process affects the surface performance of workpiece through the change of grinding force and temperature. In order to explore the mechanism of TC4 abrasive belt grinding and optimize the surface machining quality, Huang et al. [10] constructed the abrasive belt geometric model of abrasive particles per unit area based on the assumption of orderly distribution of abrasive particles and consistent contour, established the corresponding grinding numerical simulation model, predicted the grinding force and grinding temperature, and they explored the influence law of process parameters on grinding force and heat. Song et al. [11] established the thermal mechanical coupling model of abrasive belt grinding of titanium alloy, deduced the thermal mechanical coupling finite element model and equation of abrasive belt grinding, and analyzed its variation law in detail. Aiming at the experimental phenomena of over cutting and under cutting in grinding process, Yan [12] established the micro scale model of grinding force composed of sliding friction, ploughing and cutting, and explored the change law of surface roughness after improvement. Zou et al. [13] carried out experimental research on the related process of abrasive belt grinding of titanium alloy samples, and explored the influence of grinding pressure and process parameters on surface roughness. The results show that the grinding pressure has the greatest influence, followed by linear speed and feed speed. Ruzzi et al. [14] used $\mathrm{SiC}$ grinding wheel to grind Inconel 625, and explored the influence law of grinding parameters on grinding force. Grinding direction has a great influence on grinding force, and the grinding force in the reverse grinding direction is small. Dai et al. [15] established the temperature field model in the grinding process of wind turbine blade cup grinding wheel, calculated the surface grinding heat source model by calculating the material removal depth in the grinding process, and carried out numerical simulation under different grinding process parameters. Li et al. [16] used a new corundum grinding wheel to grind GH4169 nickel superalloy, and compared the effects of three different corundum grinding wheels on grinding force and grinding temperature. Sun et al. [17] explored the distribution law of dynamic grinding force and heat during disc grinding, explored the material removal mechanism of dynamic grinding force and heat 
coupling on surface quality through finite element method, and verified the effectiveness of the established model through disc grinding experiments. Wang et al. [18] analyzed in detail the evolution law of abrasive belt wear and the change process of surface texture during abrasive belt grinding, and established the relationship between abrasive belt wear and roughness. Bhaduri et al. [19] used conventional $\mathrm{SiC}$ and electroplated diamond grinding wheels $\gamma$ - The ultrasonic assisted creep grinding (UACFG) of TiAl alloy is compared with the traditional creep grinding (CFG). Compared with CFG, UACFG has lower grinding force and higher grinding ratio, and the microhardness can be increased by $8 \%$ at most. However, the disadvantage of this method is that the influence effect will be reduced with the increase of process parameters. Sun et al. [20] used the finite element analysis software ABAQUS to carry out the simulation of single particle abrasive belt grinding process for TC11 titanium alloy, analyzed the material removal process and the variation law of grinding force under different abrasives, grinding depth and grinding speed, and then obtained the action mechanism of grinding dosage on material removal efficiency and quality.

It can be seen from the research of many scholars above that there are still few studies on the grinding force and heat of workpiece in titanium alloy abrasive belt grinding and its influence of surface integrity. Therefore, based on the process method of titanium alloy abrasive belt grinding, this paper explores the influence law of different grinding parameters on grinding force and heat in the grinding process and the influence of force and heat on surface integrity. It provides a reference for grinding titanium alloy and ensuring surface quality.

\section{Grinding experiment of titanium alloy abrasive belt}

\subsection{Experimental materials}

The material used in this experiment is TC17 titanium alloy, the size specification is $400 \mathrm{~mm} \times 200 \mathrm{~mm} \times 5 \mathrm{~mm}$, and the experiment adopts the method of surface grinding. The chemical composition and physical properties of the titanium alloy at room temperature $\left(25^{\circ}\right.$ C) are shown in Table 1 and Table 2, respectively.

\subsection{Experimental equipment and methods}

In this experiment, a seven-axis six-linkage adaptive $\mathrm{CNC}$ belt grinder is used as a processing grinder. The specific structure of the grinder is shown in Fig. 1. The experiment uses $240 \#$ pyramid alumina belt for surface grinding. FC3D80 force sensor collects the force signal received by the workpiece during the grinding process and transmits it to the computer through certain processing to complete the collection of the grinding force. In the experiment, the infrared thermal imager Fluke TiR32 was used to detect the temperature of the temperature field during the grinding process, and the surface quality of the workpiece was detected by the Rtec white light interferometer, VHX-1000 super depth of field and FTS Intra surface roughness meter.

Abrasive belt grinding is known as "cold grinding". This grinding is carried out under dry grinding conditions, and the grinding force and temperature signals are detected and filtered. The detected grinding force and grinding temperature signals are shown in Fig. 2 and Fig. 3. 
Table 1 Chemical composition of titanium alloy

\begin{tabular}{ccccccc}
\hline Component & $\mathrm{Al}$ & $\mathrm{Sn}$ & $\mathrm{Zr}$ & $\mathrm{Mo}$ & $\mathrm{Gr}$ & $\mathrm{Ti}$ \\
\hline Content $(\%)$ & $4.6 \sim 5.5$ & $1.6 \sim 2.5$ & $1.8 \sim 2.8$ & $3.8 \sim 4.5$ & $3.8 \sim 4.5$ & Others \\
\hline
\end{tabular}

Table 2 Physical properties of titanium alloy

\begin{tabular}{cccccc}
\hline $\begin{array}{c}\text { Elastic modulus } \\
(\mathrm{Gpa})\end{array}$ & $\begin{array}{c}\text { Elongation } \\
(\%)\end{array}$ & $\begin{array}{c}\text { Thermal conductivity } \\
(\mathrm{W} / \mathrm{mk})\end{array}$ & $\begin{array}{c}\text { Density } \\
(\mathrm{g} / \mathrm{m} 3)\end{array}$ & $\begin{array}{c}\text { Yield strength } \\
(\mathrm{MPa})\end{array}$ & $\begin{array}{c}\text { Tensile strength } \\
(\mathrm{MPa})\end{array}$ \\
\hline 112 & 10 & 7.27 & 4.68 & 1030 & 1120 \\
\hline & &
\end{tabular}

Fig. 1 Experimental setup of abrasive belt grinding of test workpiece

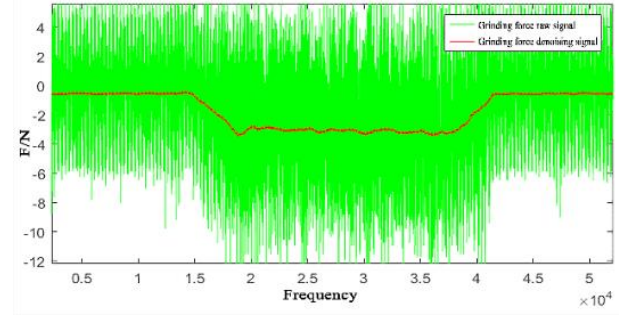

Fig. 2 Grinding force signal filter processing

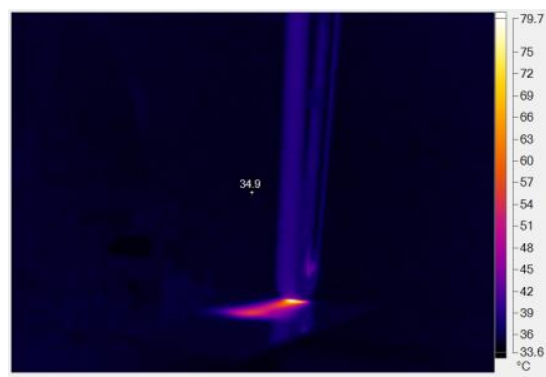

Fig. 3 Grinding temperature field signal detection

\section{Analysis of the influence of grinding process parameters on grinding force and heat}

During the grinding process, the axial force $F_{a}$ is relatively small compared to the other two forces and can be ignored in the analysis. When machining a flat workpiece, the schematic diagram of the component force and heat distribution of the grinding force between the abrasive belt and the workpiece is shown in Fig. 4.
In the figure, $V_{c}$ is the belt grinding speed, $V_{\mathrm{w}}$ is the movement speed of the plane workpiece, $a_{p}$ is the grinding depth, $F_{t}$ is the tangential force, $F_{n}$ is the normal force, $q_{a}$ is the heat taken away by the air, and $q_{b}$ is the heat flowing into the belt. , $q_{c}$ is the heat taken away by the grinding debris, and $q_{w}$ is the heat flowing into the workpiece.

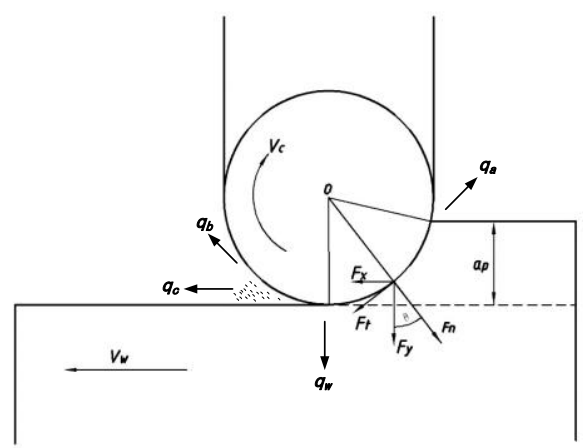

Fig. 4 Abrasive belt grinding force and grinding heat distribution

\subsection{The law of influence of process parameters on grinding force}

Fig. 5 and Fig. 6 show the variation law of grinding 
tangential force and normal force with grinding depth and belt linear speed when the feed speed is $400 \mathrm{~mm} /$ min. As can be seen from Fig. 5 (a) and Fig. 6 (a), during the process of increasing the linear speed of abrasive belt from $7.8 \mathrm{~m} / \mathrm{s}$ to $19.5 \mathrm{~m} / \mathrm{s}$, the tangential force and normal force of abrasive belt grinding gradually decrease with a small change range. When the grinding depth increases from $0.015 \mathrm{~mm}$ to $0.06 \mathrm{~mm}$, the tangential force and normal force of belt grinding increase greatly. The influence of linear speed on grinding force is not significant, and belt grinding depth plays a leading role in the change of grinding force. As can be seen from Fig. 5 (b) and Fig. 6 (b), when the linear speed of the abrasive belt is the smallest and the grinding depth is the largest, the tangential force and normal force of the abrasive belt grinding are the largest.

(a)

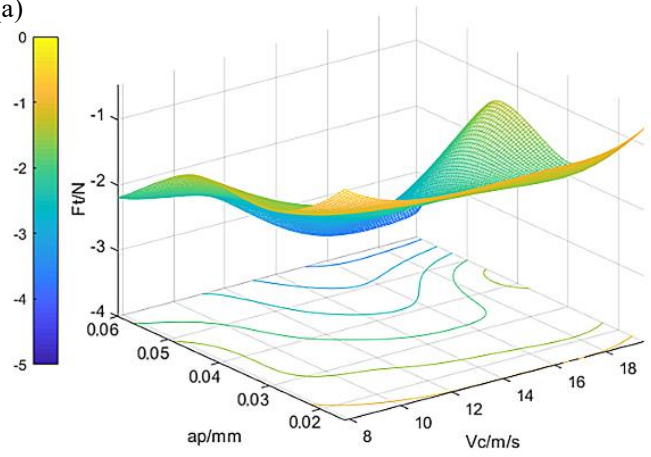

Fig. 7 shows the variation law of tangential grinding force with feed speed and belt linear speed when the normal force is about $7 \mathrm{~N}$. Observe the influence of feed speed and linear speed on grinding force. It can be seen from Fig. 7 (a) that in the grinding process, the feed speed increases from $200 \mathrm{~mm} / \mathrm{min}$ to $500 \mathrm{~mm} / \mathrm{min}$, and the tangential grinding force and normal grinding force of abrasive belt grinding gradually increase. This is because when the feed rate increases, the cutting thickness of a single abrasive particle increases, resulting in the increase of grinding force. As can be seen from Fig. 7 (b), when the feed speed is the maximum and the belt linear speed is the minimum, the belt grinding force is the maximum. From the analysis of the force data, it can be seen that the tangential force and normal force produced by belt grinding are small.

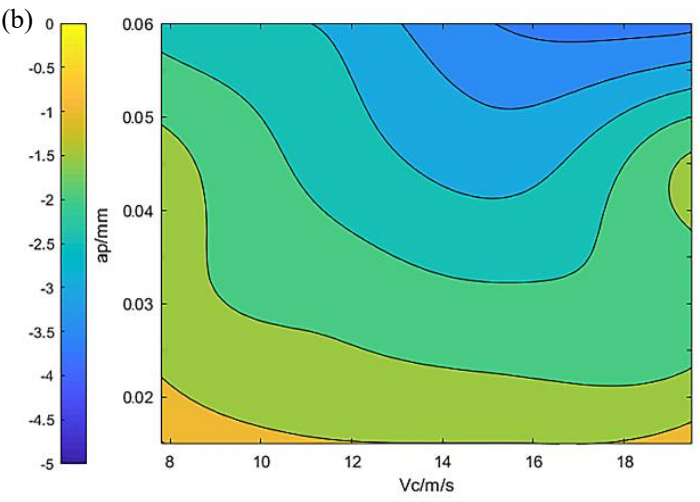

Fig. 5 Influence of belt linear speed and grinding depth on tangential grinding force

(a)

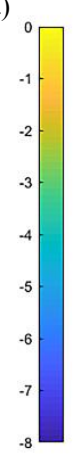

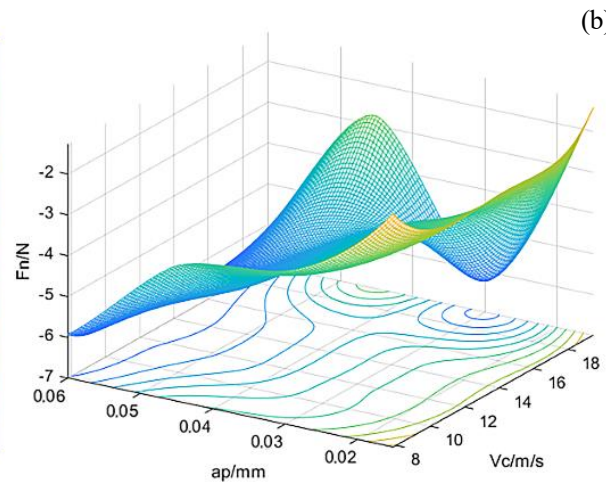
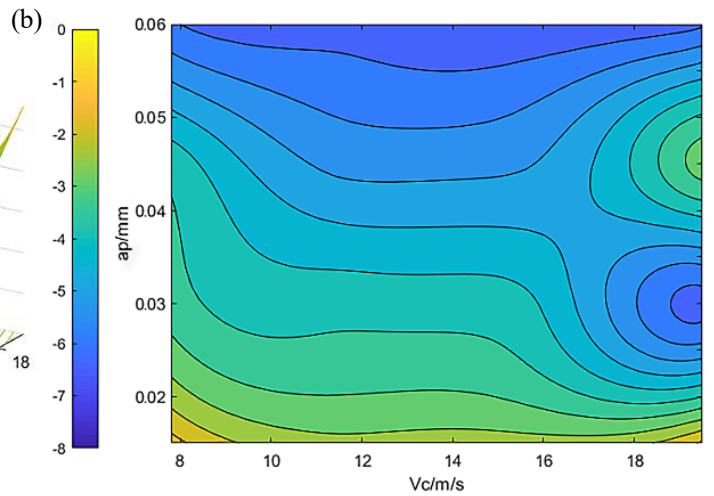

Fig. 6 The influence of belt linear speed and grinding depth on normal grinding force 
(a)

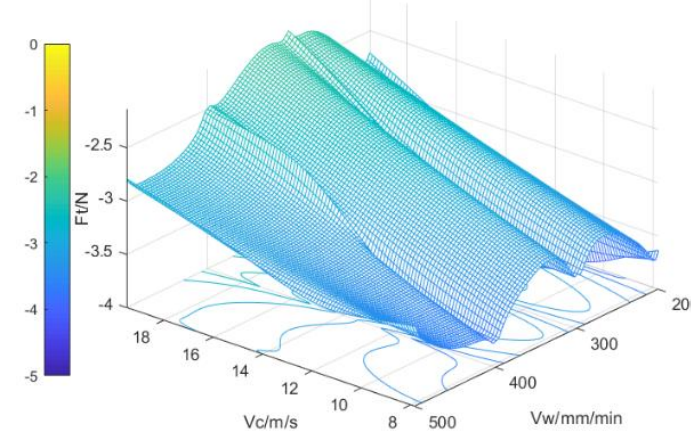

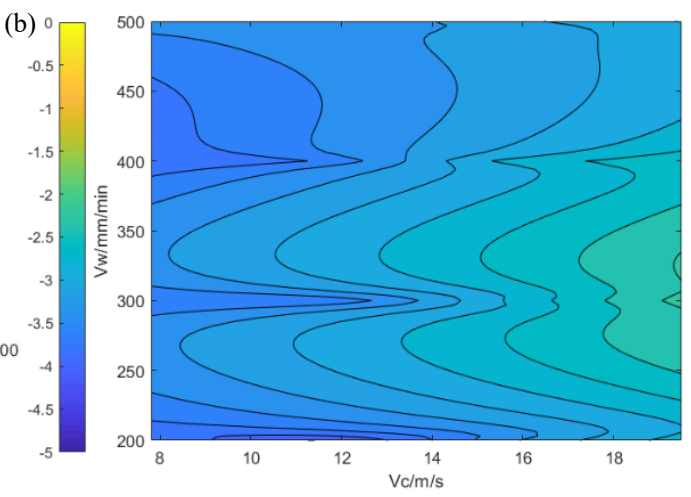

Fig. 7 The influence of feed speed and linear speed on tangential grinding force

\subsection{The law of influence of process parameters on} grinding temperature field

The article explores the influence of the grinding process parameters on the grinding temperature field.

Fig 8-10 show the changing laws of the temperature field with the belt linear velocity, feed rate and grinding depth. Abrasive belt grinding is cold grinding. The temperature of the grinding temperature field detected during the grinding process is relatively low. The increase of the belt linear speed and the increase of the grinding depth will cause the overall temperature of the grinding temperature field to rise. When the belt linear velocity increases from $7.8 \mathrm{~m} / \mathrm{s}$ to $19.5 \mathrm{~m} / \mathrm{s}$, the maximum temperature of the temperature field increases from $44.6^{\circ} \mathrm{C}$ to $65.6^{\circ} \mathrm{C}$, and the grinding depth increases from $0.02 \mathrm{~mm}$ to $0.05 \mathrm{~mm}$, the maximum temperature of the grinding temperature field increases
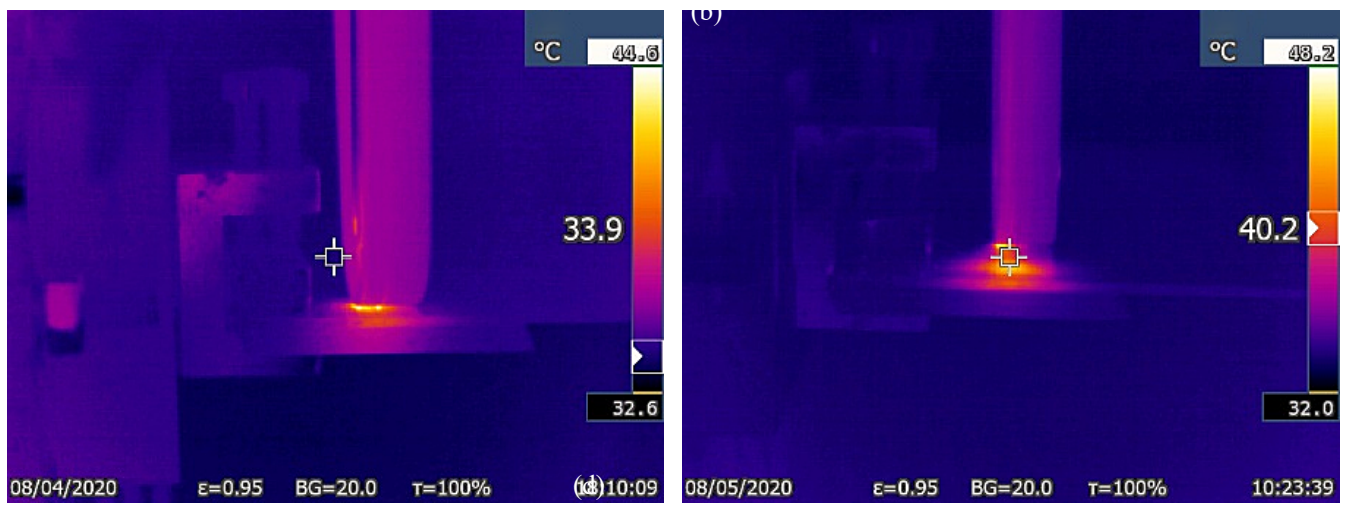


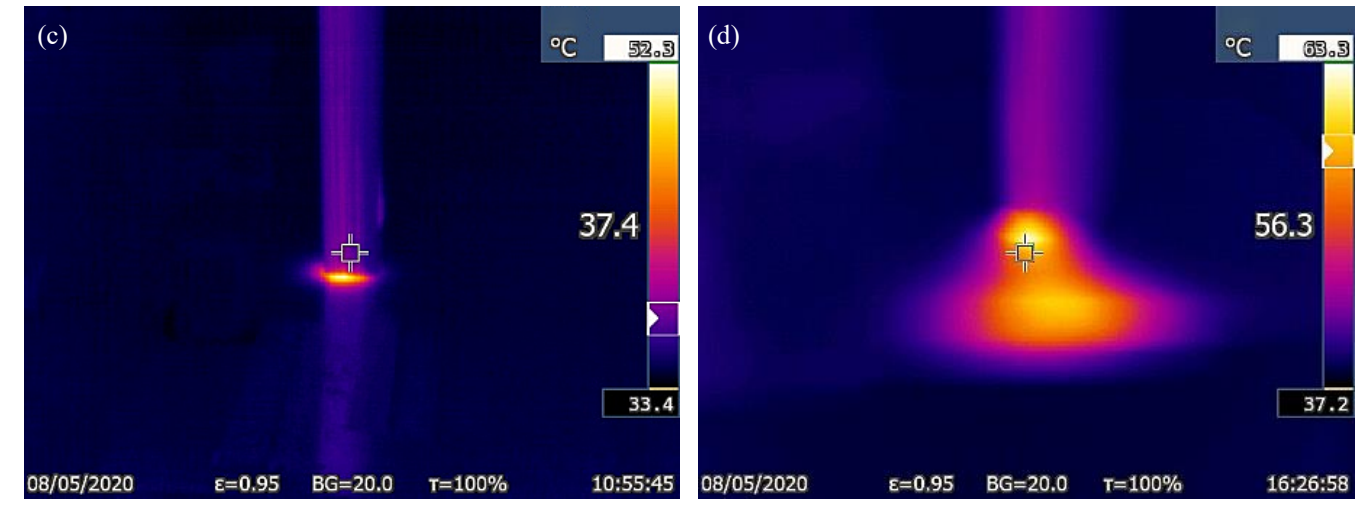

Fig. 8 Grinding temperature distribution at feed rate of $500 \mathrm{~mm} / \mathrm{min}$, grinding depth of $0.02 \mathrm{~mm}$ and linear speed of (a) $7.8 \mathrm{~m} / \mathrm{s}$, (b) $11.5 \mathrm{~m} / \mathrm{s}(\mathrm{c}), 15.6 \mathrm{~m} / \mathrm{s}$, (d) $19.5 \mathrm{~m} / \mathrm{s}$
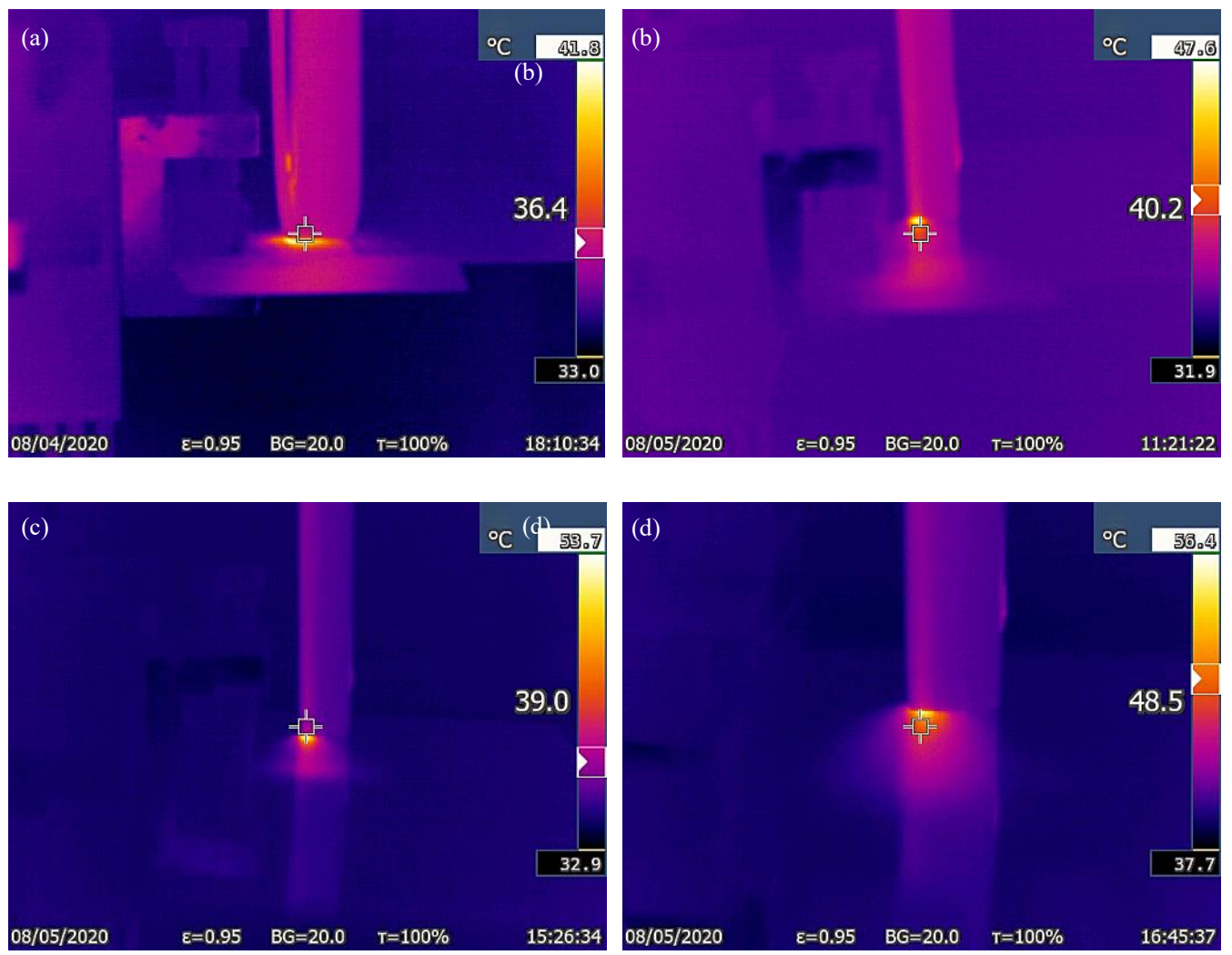

Fig. 9 Grinding temperature distribution at feed rate of (a) $500 \mathrm{~mm} / \mathrm{min}$, (b) $400 \mathrm{~mm} / \mathrm{min}$, (c) $300 \mathrm{~mm} / \mathrm{min}$, (d) $200 \mathrm{~mm} / \mathrm{min}$ grinding depth of $0.02 \mathrm{~mm}$ and linear speed of $7.8 \mathrm{~m} / \mathrm{s}$

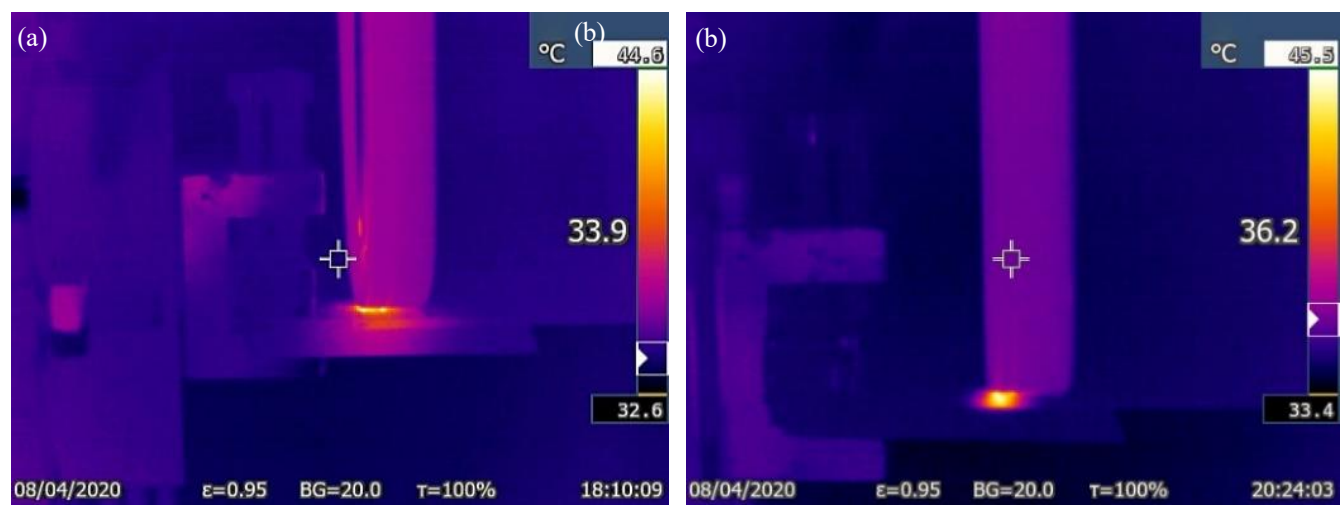



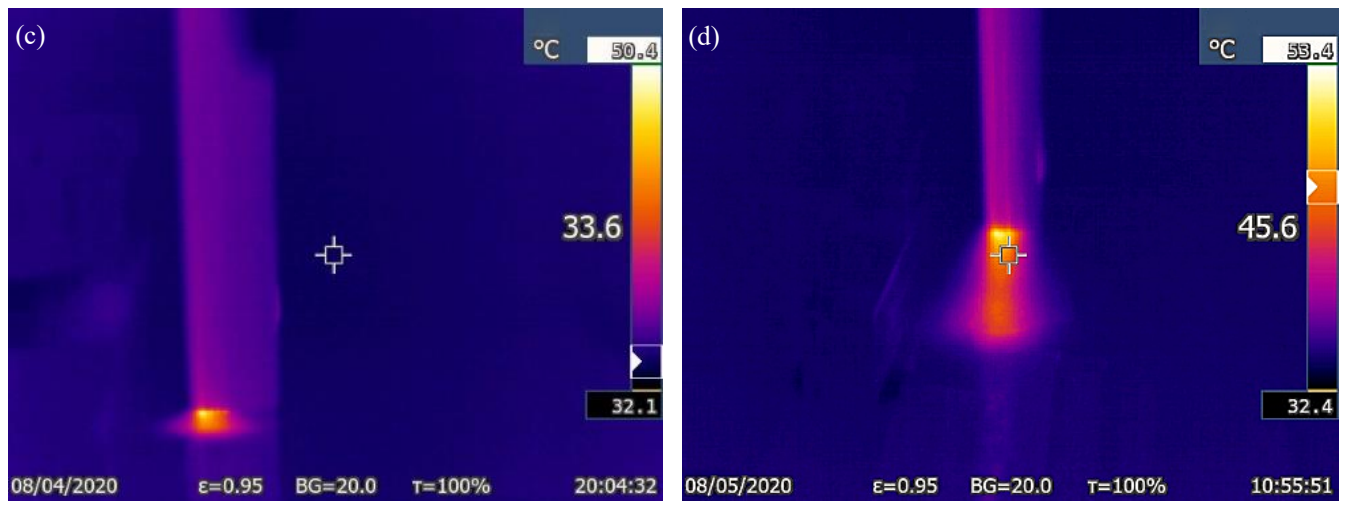

Fig. 10 Grinding temperature distribution at feed rate of $500 \mathrm{~mm} / \mathrm{min}$, grinding depth of (a) $0.02 \mathrm{~mm}$ (b) $0.03 \mathrm{~mm}$ (c) $0.04 \mathrm{~mm}$ (d) $0.05 \mathrm{~mm}$ and linear speed of $7.8 \mathrm{~m} / \mathrm{s}$

\subsection{Grinding force and grinding temperature model}

According to the influence of the above process parameters on grinding force and grinding temperature, there is a complex non-linear relationship between grinding force, grinding temperature and process parameters. In the grinding process, the grinding force is mainly related to the grinding process par-ameters and the thickness of the contact wheel. The same contact wheel is used in the experiment. According to the relationship between the grinding force and the grinding process parameters, the increase of feed speed and grinding depth will increase the grinding force, and the increase of belt linear speed will reduce the grinding force. According to the grinding force model of Huang et al. [21],

$$
\left\{\begin{array}{l}
F_{n}=U_{\mathrm{s}} \frac{V_{\mathrm{w}}^{0.84}}{V_{\mathrm{c}}} \mathrm{a}_{\mathrm{p}}^{0.68} B \\
F_{t}=U_{\mathrm{s}} \frac{V_{\mathrm{w}}^{0.84}}{V_{\mathrm{c}}^{1.15}} \mathrm{a}_{\mathrm{p}}^{0.71} B
\end{array}\right.
$$

Where, $U_{s}$ is the specific grinding energy, which is related to the properties of the material, and $B$ is the thickness of the contact wheel.

Grinding heat consists of heat flowing into the air, heat taken away by grinding debris, heat flowing into the workpiece and heat entering the contact wheel. The grinding heat is mainly the maximum temperature in the grinding area, which has the greatest impact on the surface. Based on the moving heat source theory, Rowe [22] proposed the formula of the maximum temperature $T_{\max }$ of the workpiece surface in the grinding area as follows:

$$
T_{\max }=\lambda \frac{F_{t} v_{\mathrm{c}}}{l_{c} B \beta_{\mathrm{w}}} \sqrt{\frac{l_{c}}{V_{\mathrm{w}}}}
$$

Where, $\lambda$ is the thermal conductivity, $\beta_{\mathrm{w}}$ is the thermal contact coefficient, $B$ is the belt width, and $l_{c}$ is the length of the grinding path.

According to the above grinding force and grinding temperature model, the relationship between the force and temperature model is constructed, and the coupling coefficient $\mathrm{K}$ is introduced,

$$
\left\{\begin{array}{l}
F_{t}=U_{\mathrm{s}} \frac{V_{\mathrm{w}}^{0.84}}{V_{\mathrm{c}}^{1.15} \mathrm{a}_{\mathrm{p}}^{0.71} B} \\
T_{\max }=\lambda \frac{F_{t} v_{\mathrm{c}}}{l_{c} B \beta_{\mathrm{w}}} \sqrt{\frac{l_{c}}{V_{\mathrm{w}}}} \\
F_{\mathrm{t}}=K T_{\max }
\end{array}\right.
$$

It can be seen from the formula that the coupling coefficient $K$ is a function of linear speed and feed speed, which is directly proportional to the linear speed of abrasive belt and inversely proportional to the feed speed of workpiece.

\section{Effect of grinding force and heat on surface integrity of titanium alloy}


In the process of abrasive belt grinding, due to the coupling effect of grinding temperature and grinding force, when the force and heat act on the machined surface at the same time, it leads to the change of workpiece surface quality. Higher grinding force and grinding temperature will cause huge defects such as surface cracking, serious plastic deformation and surface burn. Therefore, exploring the influence law of grinding force and heat on surface integrity is of great significance to improve the surface quality of workpiece. This section mainly explores the effects of grinding force and grinding temperature on surface roughness, surface three-dimensional morpho-logy and surface two-dimensional morphology. Temperature will cause huge defects such as surface cracking, serious plastic deformation and surface burn. Therefore, exploring the influence law of grinding force and heat on surface integrity is of great significance to improve the surface quality of workpiece. This section mainly explores the effects of grinding force and grinding temperature on surface roughness, surface three-dimensional morphology and surface two-dimensional morphology.

\subsection{Influence of grinding force and heat on surface roughness}

Surface roughness is one of the important indexes of surface quality evaluation. In this paper, the surface roughness of workpiece under different grinding temperature and grinding force is obtained through titanium alloy abrasive belt grinding experiment, as shown in Table 3. It can be seen that the influence of grinding force and temperature on surface roughness presents a non-linear relationship. Fig. 11 shows the influence of different grinding forces and grinding temperatures on the surface roughness. It can be observed that as the grinding force increases, the surface roughness of the workpiece increases from $0.699 \mu \mathrm{m}$ to $1.596 \mu \mathrm{m}$, and as the grinding force increases the change in surface roughness is more significant. This is because the greater the grinding contact force, the more conducive the abrasive belt abrasive grains to produce deeper pear grooves and greater plastic deformation, which in turn increases the highest point of the grinding surface and the distance between the lowest points is to increase the roughness value. As the grinding temperature changes, the surface roughness does not change significantly, and the surface roughness is mainly affected by the grinding force. When the grinding force is $3.429 \mathrm{~N}$, the maximum temperature of the grinding temperature field is $130.6^{\circ} \mathrm{C}$, and the surface roughness decreases from $1.596 \mu \mathrm{m}$ to $1.093 \mu \mathrm{m}$. This is related to the plastic deformation during the grinding process, because the grinding temperature during the grinding process will also cause the material to flow to both sides of the groove and curling occurs.

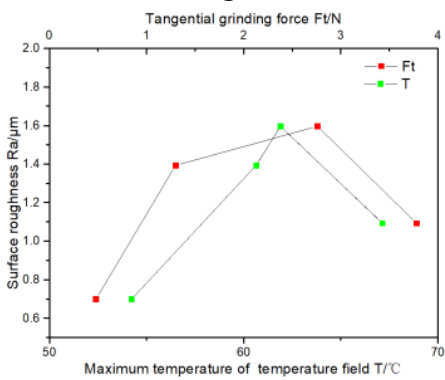

Fig. 11 Variation of surface roughness with grinding force and grinding temperature

\subsection{Influence of grinding force and heat on three- dimensional surface morphology}

The three-dimensional surface morphology is one of the important indicators for evaluating the surface integrity. Fig. 12 shows the three-dimensional surface morphology at the highest temperature of different tangential grinding forces and temperature fields. 
Table 3 Surface roughness of workpiece under different grinding force and grinding temperature

\begin{tabular}{ccc}
\hline $\begin{array}{c}\text { Maximum temperature of temperature field } \\
\left(T /{ }^{\circ} \mathrm{C}\right)\end{array}$ & $\begin{array}{c}\text { Tangential grinding force } \\
(F t / \mathrm{N})\end{array}$ & $\begin{array}{c}\text { Roughness } \\
(\mathrm{Ra} / \mu \mathrm{m})\end{array}$ \\
\hline 52.4 & 0.844 & 0.699 \\
80.2 & 2.130 & 1.393 \\
110.5 & 2.380 & 1.596 \\
130.6 & 3.429 & 1.093 \\
\hline
\end{tabular}

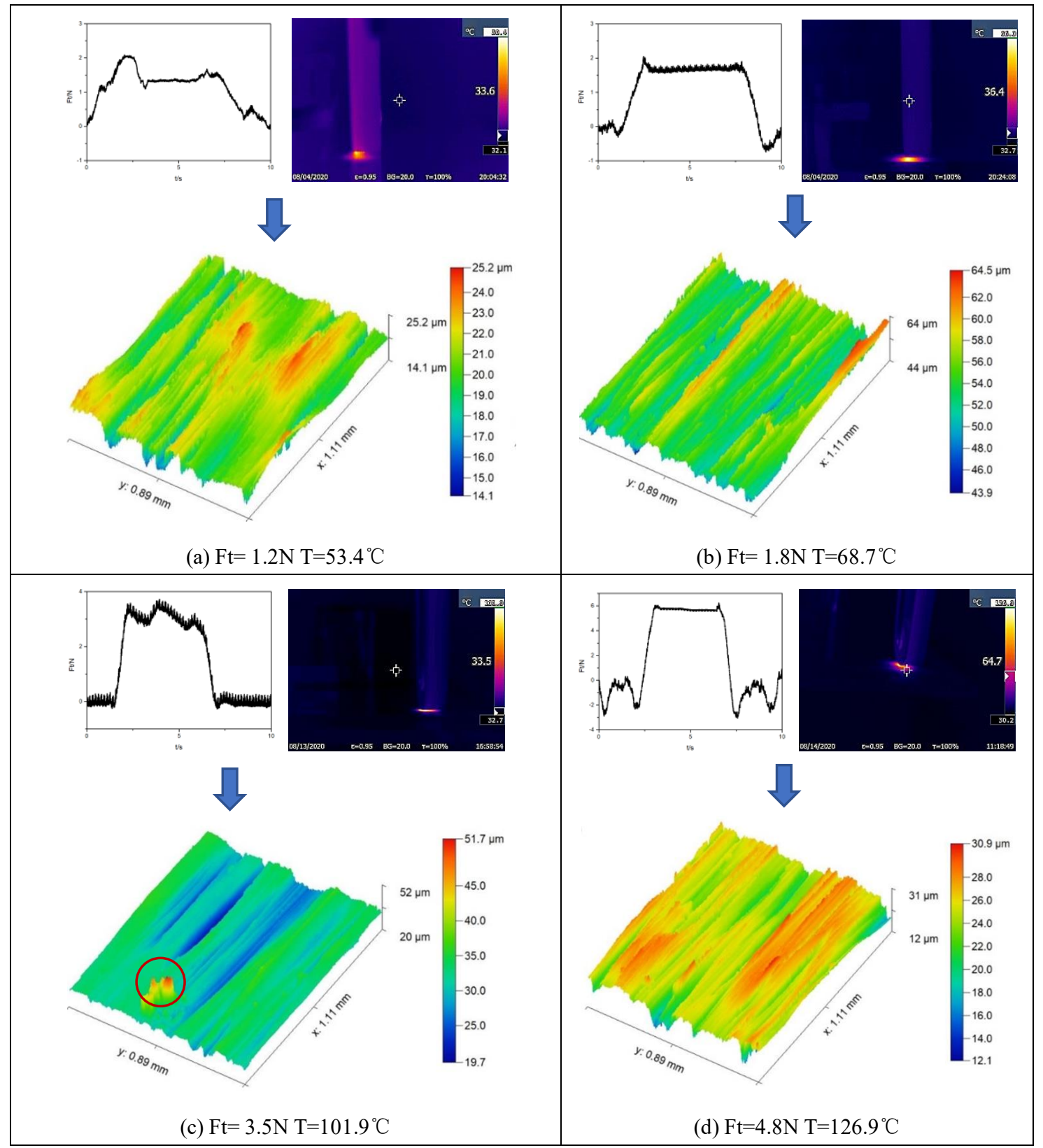

Fig. 12 Three-dimensional surface morphology under different grinding force and grinding temperature 
It can be seen from Fig. 12 that the undulation heights corresponding to the four pictures are $11.1 \mu \mathrm{m}, 20.0 \mu \mathrm{m}$, $32.0 \mu \mathrm{m}$ and $19.0 \mu \mathrm{m}$, respectively. It can be seen that as the tangential grinding force increases, the corresponding undulation height gradually increases. From the analysis in Section 3, it is concluded that reducing the linear speed of the abrasive belt, increasing the workpiece feed speed and increasing the grinding depth will increase the tangential grinding force. When reducing the linear speed of the abrasive belt, the grinding thickness of a single abrasive particle will increase, the number of abrasive particles participating in grinding per unit time will decrease, the ripple density of the grinding surface along the axial direction of the abrasive belt will decrease, and the gully length along the grinding direction will increase. When the tangential force caused by the feed rate increases, the chip thickness of a single abrasive particle increases, and when the tangential grinding force caused by the grinding depth increases, the chip thickness of a single abrasive particle also increases, which will increase the fluctuation height. In Fig. 12 (a) (c), although the material has a certain plastic deformation in the process of temperature increase, its grinding depth is small. Abrasive belt grinding is cold grinding, and the temperature generated in the grinding process is low. Therefore, the generated temperature cannot increase the plasticity of the material, and the plasticity of the material is relatively poor. Therefore, the grinding force plays a leading role in the fluctuation height. In Fig. 12 (d), due to the large grinding depth and high grinding force and grinding temperature, the grinding temperature is appropriate, which can change the plasticity of the material. Therefore, the plasticity of the material is good, and the fluctuation height of the material can be reduced during the grinding process. Moreover, it can be seen from the three figures in Fig. 12 (a) (c) that with the continuous increase of tangential grinding force, the surface texture of grinding is not clear, and the phenomenon of surface folding and wrinkling is easy to occur. The workpiece in Fig. 12 (c) has a certain bulge, which may be that the abrasive particles in the abrasive belt fall off and adhere to the work-piece.

\subsection{Influence of grinding force and heat on two- dimensional surface morphology}

Based on the observation of the two-dimensional morphology of the workpiece surface, it can be seen that the two-dimensional morphology of the workpiece surface changes significantly with the increase of grinding force and temperature. As shown in Fig. 13, the grinding force generated in the grinding process is small and the grinding temperature is relatively low, so there are no grinding cracks, but the changes of grinding force and grinding temperature lead to the generation of grinding defects. It can be seen from the figure that with the increase of grinding force and grinding temperature, more abrasive particles adhere to the workpiece surface gradually. When the grinding force is $2.15 \mathrm{~N}$ and the grinding temperature is $90^{\circ} \mathrm{C}$, the surface flatness is good. As shown in Fig. 13 (a), the surface quality is good and no defects are observed. However, when the grinding force is $3.85 \mathrm{~N}$ and the grinding temperature is 105.4 ${ }^{\circ} \mathrm{C}$, As shown in Fig. 13 (b), there are still few surface defects, and abrasive particles adhere to the workpiece surface in very few places, and when the grinding force increases to $5.5 \mathrm{~N}$, the grinding temperature increases to $135.8{ }^{\circ} \mathrm{C}$, serious defects appear on the workpiece surface. As shown in Fig. 13 (c), most of the workpiece surface is adhered to by abrasive particles, and there are burns to a certain extent. 

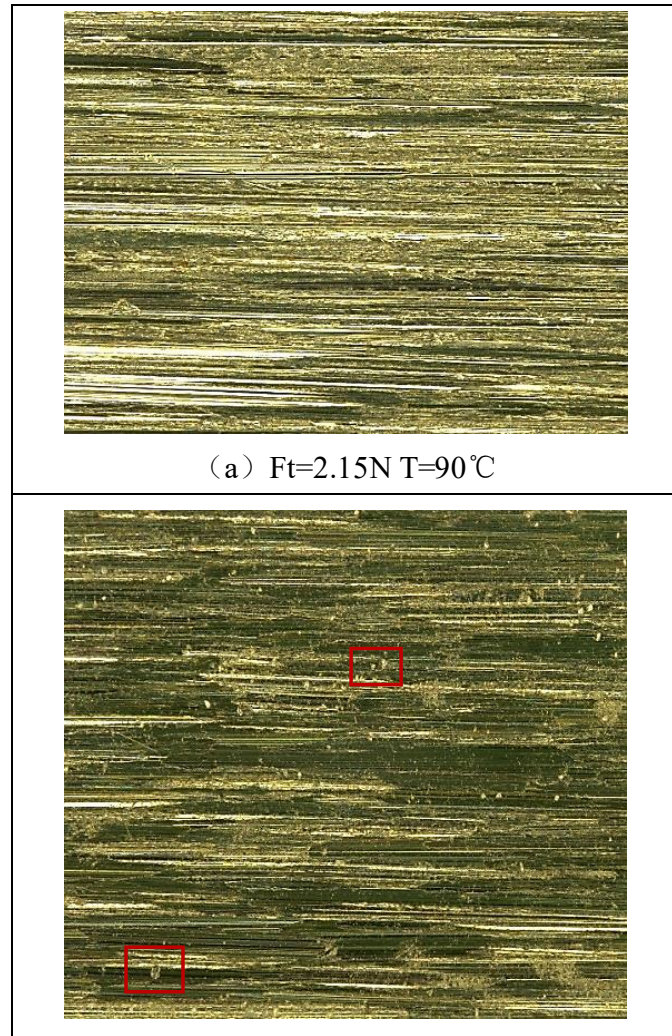

(b) $\mathrm{Ft}=3.85 \mathrm{~N} \mathrm{~T}=105.4^{\circ} \mathrm{C}$

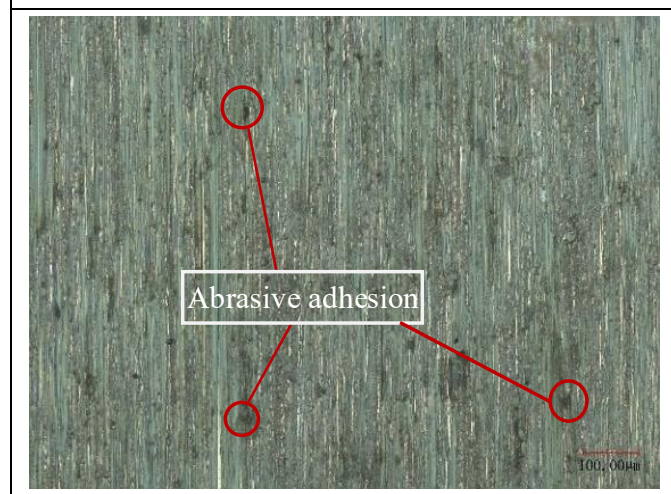

(c) $\mathrm{Ft}=5.5 \mathrm{~N} \mathrm{~T}=135.8^{\circ} \mathrm{C}$

Fig. 13 Surface morphology of workpiece under different

grinding force and grinding temperature

\section{Conclusion}

In this paper, the grinding experiment of titanium alloy abrasive belt is carried out, and the effects of process parameters on grinding force and heat and force and heat on workpiece surface integrity are explored. The following conclusions can be drawn.

(1) With the decrease of belt linear speed, the increase of workpiece feed speed and grinding depth, the belt grinding force increases gradually. The grinding depth has the most significant effect on the change of grinding force.
(2) With the decrease of belt linear speed, the increase of workpiece feed speed and the increase of grinding depth, the belt grinding temperature increases gradually, but the overall grinding temperature field is low, all within $150^{\circ} \mathrm{C}$.

(3) With the increase of grinding force and grinding temperature, the surface roughness gradually increases and the surface fluctuation height increases. However, when the temperature rises to more than $120^{\circ} \mathrm{C}$, the surface roughness decreases and the surface fluctuation height decreases. The reason may be that the temperature changes the plasticity of the workpiece.

(4) With the increase of grinding force and temperature, the surface morphology of the workpiece gradually becomes worse. When the grinding force reaches $5.5 \mathrm{~N}$ and the grinding temperature reaches $135.8^{\circ} \mathrm{C}$, there are a certain degree of burns and more surface defects.

\section{Declaration}

Ethical Approval: Ethical approval was not required for this study.

Consent to Participate: Written informed consent was obtained from individual or guardian participants.

Consent to Public: Manuscript was approved by all authors for publication.

Authors Contributions: Ying Liu: Investigation, Writing original draft, Visualization. Jiayu Xu: Writing review \& editing, Experiment. Guijian Xiao: Investigation, Methodology, Funding acquisition. Kun Zhou: Project administration, Resources, Experiment. Gang Liu: Data curation, Supervision, Validation, Experiment.

Funding: The authors would like to gratefully acknowledge the financial from the National Natural Science Foundation of China (52175377), the National Science and Technology Major Project (2017-VII-00020095), the Graduate scientific research and innovation foundation of Chongqing (CYB20009) and the Special Supported Project of Chongqing Postdoctoral Research Program (XmT2020028) 
Competing Interests: The authors have no known competing financial interests or personal relationships that could have appeared to influence the work reported in this paper.

Availability of data and materials: The datasets used or analyzed during the current study are available from the corresponding author on reasonable request.

\section{References}

1. Qian N, Fu Y, Zhang Y, Chen J, Xu J (2019) Experimental investigation of thermal performance of the oscillating heat pipe for the grinding wheel. Int $\mathrm{J}$ Heat Mass Transf 136:911-923.

2. Yang H, Ding W, Chen Y, Laporte S, Xu J, Fu Y (2019) Drilling force model for forced low frequency vibration assisted drilling of Ti-6Al-4V titanium alloy. Int J Mach Tools Manuf 146:103438.

3. Yu C, Hong J, Fang H (2006) Experimental Study on Creep Feed Deep Grinding Titanium Alloy with Slotted CBN Grinding Wheel. Key Engineering Materials 304:166-170.

4. Nosenko S, Nosenko V, Bairamov A(2015) Factors affecting the surface roughness in the deep grinding of titanium alloys. Russian Engineering Research 35(7):549553.

5. Nosenko S, Nosenko V, Kremenetskii L(2014) Influence of dressing of the wheel on the surface quality of titanium alloy in deep grinding. Russian Engineering Research 34(10):632-636.

6. Gong M, Zou L, Nan L, et al (2020) Investigation on secondary self-sharpness performance of hollow-sphere abrasive grains in belt grinding of titanium alloy. J Manuf Process 29:68-75.

7. Zhou K, Liu J, Xiao G, et al (2021) Probing residual stress evolution of titanium alloy due to belt grinding based on molecular dynamics method. J Manuf Process 66:446-459.

8. Zhu D, Luo S, Yang L, et al (2015) On energetic assessment of cutting mechanisms in robot-assisted belt grinding of titanium alloys. Tribol Int 90:55-59.

9. Yao C, Jin Q, Huang X, et al (2013) Research on surface integrity of grinding Inconel718. Int J Adv Manuf Technol 65(5/8): 1019-1030.

10. Huang Z, Dong H, Zhou Z, et al (2018) Modeling and Prediction of Grinding Force on Belt Grinding TC4. Surface Technology 47(9):250-258.

11. Song K, Xiao G, Chen S, et al (2021). Analysis of thermalmechanical causes of abrasive belt grinding for titanium alloy. Int J Adv Manuf Technol 113: 3241-3260.

12. Yan $\mathrm{S}, \mathrm{X} \mathrm{Xu}$, Yang Z, et al (2019). An improved robotic abrasive belt grinding force model considering the effects of cut-in and cut-off. J Manuf Process 37:496-508.

13. Luo G, Zou L, Huang Y, et al (2020) Study on material removal and surface quality in titanium alloy grinding with alumina hollow-sphere abrasive belt. China Mechanical Engineering 31(19):2363-2370.

14. Ruzzi R, Silva R, Silva L, et al(2020). Influence of grinding parameters on Inconel 625 surface grinding. J Manuf Process 55: 174-185.

15. Dai S, Wang X, Zhang H, et al (2020) Research on variation of grinding temperature of wind turbine blade robotic grinding. Proceedings of the Institution of Mechanical Engineers Part B Journal of Engineering Manufacture 235:367-377.

16. Li B, Ding W, Ma Y, et al (2021) Performance evaluation on grinding of nickel-based superalloy GH4169 using new corundum abrasive wheel. Aeronautical Manufacturing Technology 64(4): 14-19.

17. Sun C, Lu Y, Xiu S, et al (2021) Analysis on the removal mechanism of disc grinding based on dynamic thermalmechanical coupling. International Journal of Mechanics and Materials in Design, 1-23. 
18. Wang W, Salvatore F, Rech J, and Li J (2018) Comprehensive investigation on mechanisms of dry belt grinding on AISI52 100 hardened steel. Tribol Int 121:310320.

19. Bhaduri D, Soo S, Aspinwall D, et al (2017) Ultrasonic assisted creep feed grinding of gamma titanium aluminide using conventional and super-abrasive wheels. CIRP Ann Manuf Technol 66:341-344.
20. Sun J, Qu Z, Zhang L (2017) Simulation of Single Abrasive Grain Belt Grinding of TC11 Based on ABAQUS Aerospace Manufacturing Technology 6:21-25.

21. Huang Y, Zhu P. Principle and application of abrasive belt grinding. Chongqing University Press, 1993.

22. Rowe W (2001) Thermal analysis of high efficiency deep grinding. Int J Mach Tools Manuf 41(1):1-19. 